\title{
Nanoporous Quasi-High-Entropy Alloy Microspheres
}

\author{
Lianzan Yang ${ }^{1,2,+} \mathbb{C}$, Yongyan $\mathrm{Li}^{1,+}$, Zhifeng Wang ${ }^{1,2, * \mathbb{C}}$, Weimin Zhao ${ }^{1, *}$ and Chunling Qin ${ }^{1} \mathbb{D}$ \\ 1 School of Materials Science and Engineering, Hebei University of Technology, Tianjin 300130, China; \\ yanglianzan@163.com (L.Y.); liyongyan@126.com (Y.L.); clqin@hebut.edu.cn (C.Q.) \\ 2 Key Laboratory for New Type of Functional Materials in Hebei Province, Hebei University of Technology, \\ Tianjin 300130, China \\ * Correspondence: zfwangmail@163.com (Z.W.); wmzhao@yahoo.com (W.Z.); \\ Tel.: +86-22-6020-4129 (Z.W.); +86-22-6020-4477 (W.Z.) \\ + These authors contributed equally to this work.
}

Received: 13 February 2019; Accepted: 18 March 2019; Published: 19 March 2019

\begin{abstract}
High-entropy alloys (HEAs) present excellent mechanical properties. However, the exploitation of chemical properties of HEAs is far less than that of mechanical properties, which is mainly limited by the low specific surface area of HEAs synthesized by traditional methods. Thus, it is vital to develop new routes to fabricate HEAs with novel three-dimensional structures and a high specific surface area. Herein, we develop a facile approach to fabricate nanoporous noble metal quasi-HEA microspheres by melt-spinning and dealloying. The as-obtained nanoporous $\mathrm{Cu}_{30} \mathrm{Au}_{23} \mathrm{Pt}_{22} \mathrm{Pd}_{25}$ quasi-HEA microspheres present a hierarchical porous structure with a high specific surface area of $69.5 \mathrm{~m}^{2} / \mathrm{g}$ and a multiphase approximatively componential solid solution characteristic with a broad single-group face-centered cubic XRD pattern, which is different from the traditional single-phase or two-phase solid solution HEAs. To differentiate, these are named quasi-HEAs. The synthetic strategy proposed in this paper opens the door for the synthesis of porous quasi-HEAs related materials, and is expected to promote further applications of quasi-HEAs in various chemical fields.
\end{abstract}

Keywords: dealloying; nanoporous materials; high-entropy alloys

\section{Introduction}

High-entropy alloys (HEAs) are equimolar or near-equiatomic solid solution alloys with four or more elements [1,2]. Due to the high mixing entropy, the physical and chemical properties of HEAs are quite different compared to traditional alloys. In particular, the mechanical properties of HEAs have been extensively studied and exploited. It was found that refractory NbMoTaW HEA pillars [1] presented extraordinarily high yield strengths of $\sim 10 \mathrm{GPa}$ and enhanced stability at high temperature. The $\mathrm{CrMnFeCoNi} \mathrm{HEA} \mathrm{showed} \mathrm{improved} \mathrm{mechanical} \mathrm{properties} \mathrm{at} \mathrm{cryogenic}$ temperatures [3]. A metastable $\mathrm{Fe}_{50} \mathrm{Mn}_{30} \mathrm{Co}_{10} \mathrm{Cr}_{10}$ dual-phase HEA was developed to overcome the strength-ductility trade-off [4]. More and more influential work related to the fabrication, phase transformation, and mechanical properties of HEAs has been reported [5-7]. However, the chemical properties of HEAs have long been neglected due to the low specific surface area, limited by traditional synthesis methods. Recently, carbon-nanofiber-loaded HEA nanoparticles composite with a high specific surface area exhibited excellent selectivity and stability as ammonia oxidation catalysts [8]. To help HEAs shine in broader chemical applications, it is important to develop various HEAs with new three-dimensional (3D) structures and a high specific surface area.

Nanoporous materials usually possess a high specific surface area $[9,10]$. However, traditional methods for preparing porous metals cannot be mechanically duplicated to acquire nanoporous HEAs. Moreover, to our knowledge, there has still been no report on the fabrication of nanoporous HEAs. 
Here we report the successful synthesis of nanoporous $\mathrm{Cu}-\mathrm{Au}-\mathrm{Pt}-\mathrm{Pd}$ quasi-HEA microspheres by combining melt-spinning and dealloying processes for the first time. The as-prepared quasi-HEA presents a nearly equal atom ratio and a special multiphase approximatively componential solid solution structure with a broad single-group face-centered cubic XRD pattern. The strategy opens the door for the fabrication of various nanoporous noble metal based quasi-HEAs, and may promote the application of (quasi-)HEAs in the catalysis, sensor, and surface-enhanced Raman scattering fields.

\section{Materials and Methods}

$\mathrm{Cu}_{97} \mathrm{Au}_{1} \mathrm{Pt}_{1} \mathrm{Pd}_{1}$ (at.\%) ingots were first produced by arc-melting of $\mathrm{Cu}, \mathrm{Au}, \mathrm{Pt}$, and $\mathrm{Pd}(99.99 \mathrm{wt} . \%)$ ingots. This starting alloy composition is designed and inspired by a previous work [11]. In this situation, a small ligament/pore structure can be obtained after dealloying. Then a melt-spinning process $[12,13]$ was performed to obtain the precursor microspheres. In particular, to guarantee the formation of microspheres in the rapid solidification process, the tangent speed of the copper wheel is set to $3000 \mathrm{r} / \mathrm{min}$ and the gas pressure for spraying is $1.5 \mathrm{MPa}$. Finally, nanoporous quasi-HEA microspheres were fabricated by free dealloying [14-16] of the precursor microspheres in a $2 \mathrm{M} \mathrm{HNO}_{3}$ solution for $24 \mathrm{~h}$. The preparation process is shown in Figure 1.

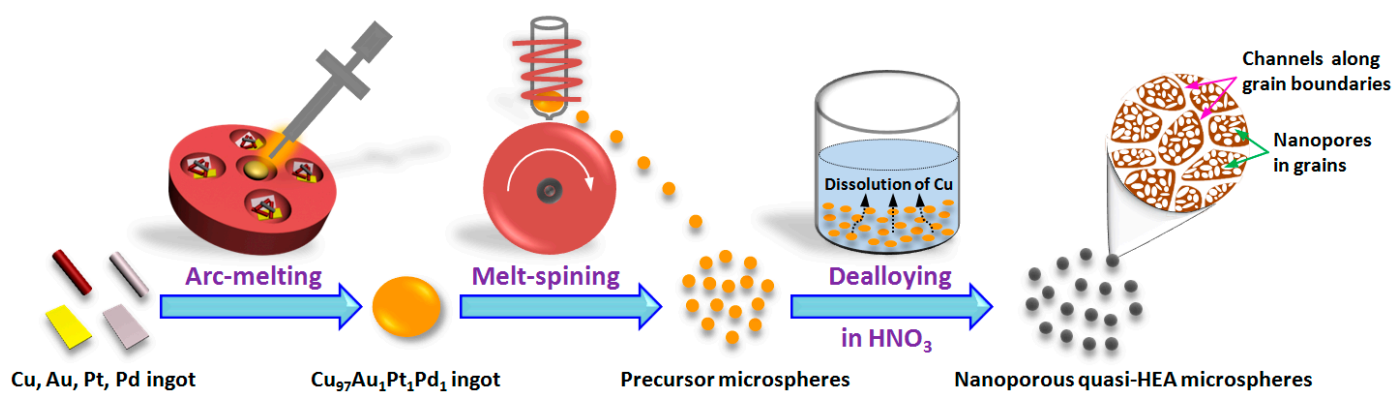

Figure 1. The synthesis process of nanoporous quasi-HEA microspheres.

The phase composition of samples was verified by an X-ray diffractometer (XRD, D8-Advance Bruker, Karlsruhe, Germany) using $\mathrm{Cu} \mathrm{K} \alpha$ radiation at a step rate of $10^{\circ} / \mathrm{min}$. The chemical valence state of samples was examined by X-ray photoelectron spectroscopy (XPS, Thermo Fisher Scientific, Waltham, MA, USA). The morphology and chemical composition of samples were characterized by scanning electron microscopy (SEM, Nova nanoSEM 450, 2 kV, FEI, Hillsboro, OR, USA) equipped with an X-ray energy dispersive spectroscope (EDS, Oxford Instruments, Oxford, UK) and transmission electron microscopy (TEM, JEM-2010F, JEOL, Tokyo, Japan). The surface area and pore size distributions of samples were determined by using the Brunauer-Emmett-Teller (BET) or Barrett-Joyner-Halenda (BJH) method, respectively. The particle size and ligament/pore size distribution were measured by Nano Measurer V1.2, software created by Fudan University, Shanghai, China.

\section{Results and Discussion}

Figure 2a shows the XRD patterns of the microspheres before and after dealloying. Since the content of $\mathrm{Cu}$ is as high as 97 at.\% in the precursor, the peak positions are very close to pure $\mathrm{Cu}$. After dealloying, the obvious broad diffraction peaks at $40.7^{\circ}, 46.8^{\circ}, 68.2^{\circ}$, and $83.0^{\circ}$ can be indexed as (111), (200), (220), and (311) planes of a single-group face-centered cubic (FCC) structure respectively. It is reported that multicomponent noble metal solid solutions usually present broad but not very sharp peaks $[17,18]$ compared with the traditional crystalline XRD patterns with sharp peaks. So the solid solution structure of the as-dealloyed material can be confirmed according to the characteristic of the broad diffraction peaks. In comparison with the XRD spectra of the precursor microspheres, the diffraction peaks of the dealloyed microspheres shift to the lower diffraction angles. This is mainly due to the removal of a large amount of $\mathrm{Cu}$, which is consistent with the EDS results in Figure $2 b$,c. 
According to the EDS results, as shown in Figure $2 b, c$, the composition of microspheres changes from $\mathrm{Cu}_{97.1} \mathrm{Au}_{1.0} \mathrm{Pt}_{0.9} \mathrm{Pd}_{1.0}$ (near the target ratio) to $\mathrm{Cu}_{30.2} \mathrm{Au}_{22.9} \mathrm{Pt}_{22.0} \mathrm{Pd}_{24.9}$ (denoted as $\mathrm{Cu}_{30} \mathrm{Au}_{23} \mathrm{Pt}_{22} \mathrm{Pd}_{25}$ ) after dealloying.
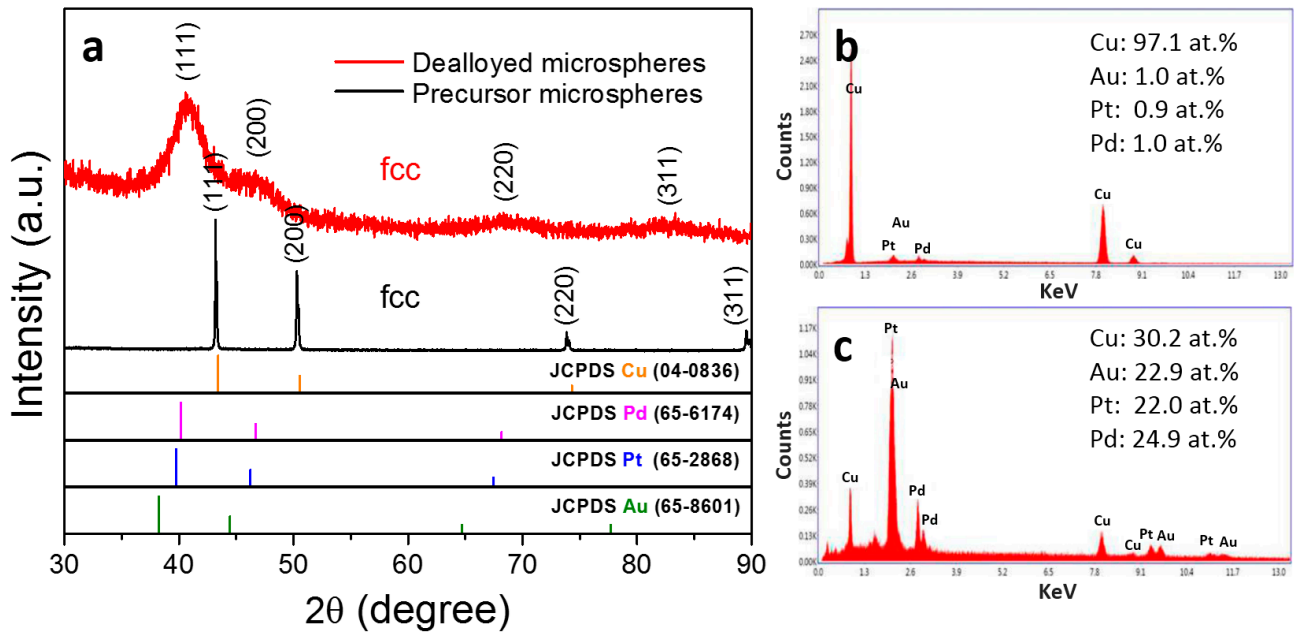

Figure 2. (a) XRD patterns of the precursor microspheres before and after dealloying in $2 \mathrm{M} \mathrm{HNO}_{3}$ for $24 \mathrm{~h}$. EDS analysis of the precursor microspheres before (b) and after (c) dealloying in $2 \mathrm{M} \mathrm{HNO}_{3}$ for $24 \mathrm{~h}$.

In order to predict the formation of solid solution structure in the dealloyed microspheres, typical physical parameters including $\Delta S_{\text {mix }}, \Delta H_{\text {mix }}, \delta$ and $\Omega$ of the product as well as other reported HEAs are calculated by Equations (1)-(4) [19-21]:

$$
\begin{gathered}
\Delta S_{\text {mix }}=-R \sum_{i=1}^{n} c_{i} \ln c_{i} \\
\Delta H_{\text {mix }}=\sum_{i=1, i \neq j}^{n} 4 \Delta H_{i j}^{\text {mix }} c_{i} c_{j} \\
\delta=\sqrt{\sum_{i=1}^{n} c_{i}\left(1-r_{i} /\left(\sum_{i=1}^{n} c_{i} r_{i}\right)\right)^{2}} \\
\Omega=T_{\mathrm{m}} \Delta S_{\text {mix }} /\left|\Delta H_{\text {mix }}\right|
\end{gathered}
$$

where $\Delta S_{\text {mix }}$ is the mixing entropy of the alloying elements, $\Delta H_{\text {mix }}$ is the enthalpy of mixing, $\delta$ is the atomic size difference, $\Omega$ is a special parameter defined to predict the solid solution formation, $n$ is the total number of components in a system, $R\left(8.31 \mathrm{~J} \cdot \mathrm{K}^{-1} \cdot \mathrm{mol}^{-1}\right)$ is the gas constant, $c_{i}$ is the molar ratio of the $i$ th component, $r_{i}$ is the atomic radius of the $i$ th component, $\Delta H_{i j}^{\text {mix }}$ is the enthalpy of mixing between $i$ and $j$ elements, and $T_{\mathrm{m}}$ is the average melting point. It was proposed [22] that the HEAs with simple solid solution structures tend to form when the following empirical rules can be satisfied simultaneously: $\Delta S_{\text {mix }}>11.3 \mathrm{~J} \cdot \mathrm{K}^{-1} \cdot \mathrm{mol}^{-1},-15 \mathrm{~kJ} \cdot \mathrm{mol}^{-1}<\Delta H_{\text {mix }}<5 \mathrm{~kJ} \cdot \mathrm{mol}^{-1}, \delta<6.6$ and $\Omega>1.1$.

\begin{tabular}{|c|c|c|c|c|c|c|}
\hline Alloy & Phase & $\begin{array}{c}\Delta S_{\mathrm{mix}} \\
\left(\mathrm{J} \cdot \mathrm{K}^{-1} \cdot \mathrm{mol}^{-1}\right)\end{array}$ & $\underset{\left(\mathrm{kJ} \cdot \mathrm{mol}^{-1}\right)}{\Delta H_{\text {mix }}}$ & $\delta$ & $\Omega$ & Reference \\
\hline $\mathrm{Al}_{0.375} \mathrm{CoCrFeNi}$ & FCC & 13.0 & -8.1 & 4.1 & 2.4 & [23] \\
\hline $\mathrm{CoCrFeNi}$ & FCC & 11.6 & -3 & 1.3 & 6.1 & [24] \\
\hline $\mathrm{AuPdAgPt}$ & FCC & 11.6 & -2 & 2.2 & 7.9 & [25] \\
\hline $\mathrm{Cu}_{30} \mathrm{Au}_{23} \mathrm{Pt}_{22} \mathrm{Pd}_{25}$ & FCC & 11.5 & -8.6 & 2.3 & 1.8 & This work \\
\hline
\end{tabular}
Table 1 lists the above calculated physical parameters of the product and other reported HEAs [23-25], indicating that the composition of the product satisfies the empirical rules for the formation of HEAs.

Table 1. Calculated parameters of the quasi-HEA microspheres and other reported HEAs. 
To further investigate the chemical valence states of metal elements in the product, XPS detection was carried out (Figure 3). The XPS fully scanned spectra (Figure 3a) show predominant signals of Au, $\mathrm{Cu}, \mathrm{Pd}, \mathrm{Pt}, \mathrm{C}$ (from the atmosphere), and $\mathrm{O}$, indicating that no other impurity elements are present. As shown in Figure 3b, the two peaks located at 84.2 and $87.9 \mathrm{eV}$ can be attributed to $\mathrm{Au} 4 \mathrm{f}_{7 / 2}$ and $\mathrm{Au} 4 \mathrm{f}_{5 / 2}$ of $\mathrm{Au}^{0}$, respectively [26]. The $\mathrm{Pt} 4 \mathrm{f}$ spectra (Figure 3c) shows two strong peaks at binding energies of 71.1 and $74.5 \mathrm{eV}$, corresponding to $\mathrm{Pt} 4 \mathrm{f}_{7 / 2}$ and $\mathrm{Pt}_{4 \mathrm{f}_{5 / 2}}$ of $\mathrm{Pt}^{0}$, while two weak peaks at 72.0 and $75.4 \mathrm{eV}$ are attributed to $\mathrm{Pt}^{2+} 4 \mathrm{f}_{7 / 2}$ and $4 \mathrm{f}_{5 / 2}$, respectively [27]. For the $\mathrm{Pd} 3 \mathrm{~d}_{5 / 2}$ spectra shown in Figure $3 \mathrm{~d}$, two peaks located at 335.7 and $336.5 \mathrm{eV}$ can be assigned to $\mathrm{Pd}^{0}$ and $\mathrm{Pd}^{2+}$, respectively [28]. Similarly, the two peaks located at 932.5 and $934.4 \mathrm{eV}$ are attributed to $\mathrm{Cu}^{0}$ and $\mathrm{Cu}^{2+}$ of $\mathrm{Cu} 2 \mathrm{p}_{3 / 2}$, respectively (Figure 3e) [29]. The shift of the binding energies of $\mathrm{Au}, \mathrm{Pt}, \mathrm{Pd}$, and $\mathrm{Cu}$ in the product indicates the evident change in the electronic structure, probably owing to the formation of a solid solution structure [30,31]. The existence of very few divalent metals can be attributed to the oxidation of surface elements in air [29]. By calculating the peak areas of $\mathrm{M}^{0}$ and $\mathrm{M}^{2+}$, the results show the percentage of $\mathrm{Cu}^{0}, \mathrm{Pd}^{0}$, and $\mathrm{Pt}^{0}$ species are $63.3 \%, 67.7 \%$, and $78.5 \%$, respectively, indicating that the dealloyed microspheres are mainly in zero valence state.
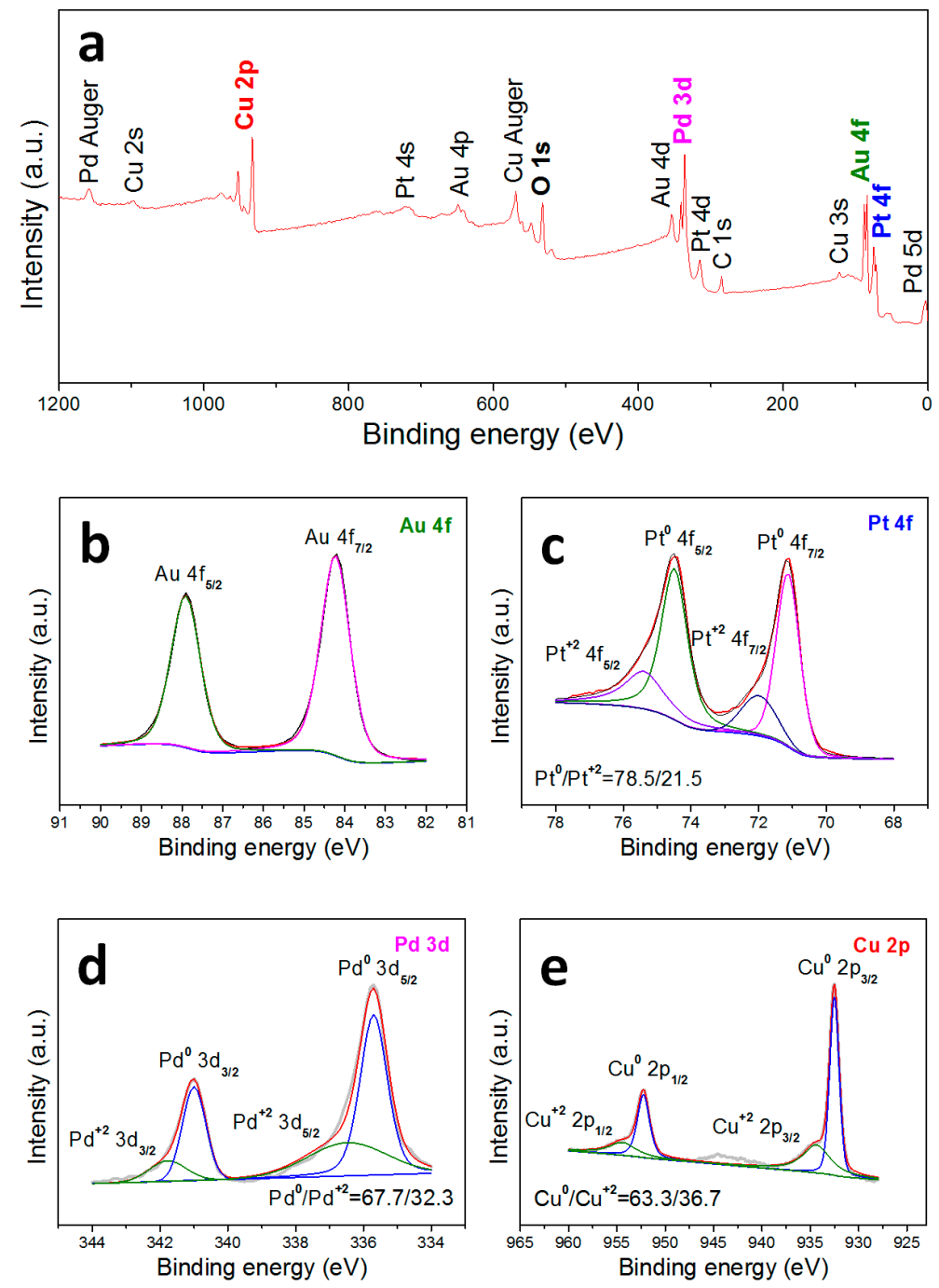

Figure 3. XPS spectra of the precursor microspheres after dealloying in $2 \mathrm{M} \mathrm{HNO}_{3}$ for $24 \mathrm{~h}$ : (a) fully scanned spectra; (b) Au 4f; (c) Pt 4f; (d) Pd 3d; (e) Cu 2p.

When conducting further investigation into the porous structure of the as-fabricated samples, nitrogen adsorption-desorption isotherms analysis was employed (Figure 4a). In Figure 4a, a kind 
of type-IV isotherm characterized by a distinct hysteresis loop [32] was observed, indicating the mesoporous nature of the material. This corresponds well with the pore diameter distribution curve displayed in Figure 4b. The pore size of samples mainly ranges from 4 to $20 \mathrm{~nm}$, and the peak size is about $7.9 \mathrm{~nm}$. Due to the above porous structure characteristics, the specific surface area obtained by BET method reaches $69.5 \mathrm{~m}^{2} / \mathrm{g}$.
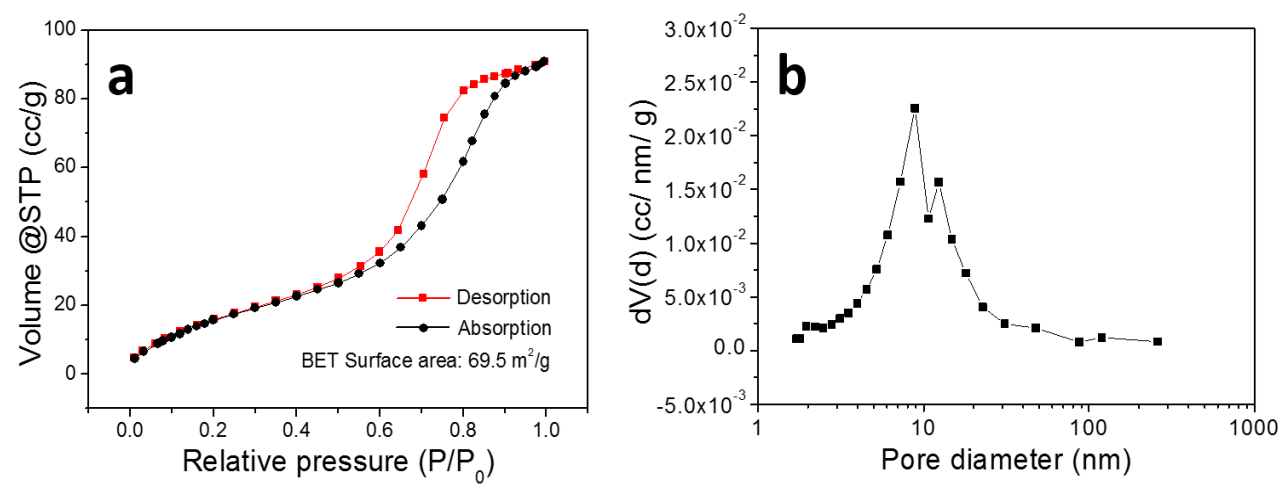

Figure 4. $\mathrm{N}_{2}$ adsorption desorption isotherms (a) and corresponding BJH pore size distribution curves (b) of nanoporous quasi-HEA microspheres.

Figure 5 shows the SEM image of the microspheres with a histogram of microsphere size distribution. One can see that the shape of the precursor is regular and spherical (Figure 5a). After dealloying, the diameter of parts of microspheres decreases (Figure 5b). The size statistics in Figure $5 c$ show that the diameter of the precursor mainly ranges from 70 to $100 \mu \mathrm{m}$, with an average diameter of $86 \mu \mathrm{m}$. After dealloying, though the main diameter range of microsphere stays around 70-100 $\mu \mathrm{m}$, the ratio of microspheres with diameter less than $80 \mu \mathrm{m}$ increases slightly.
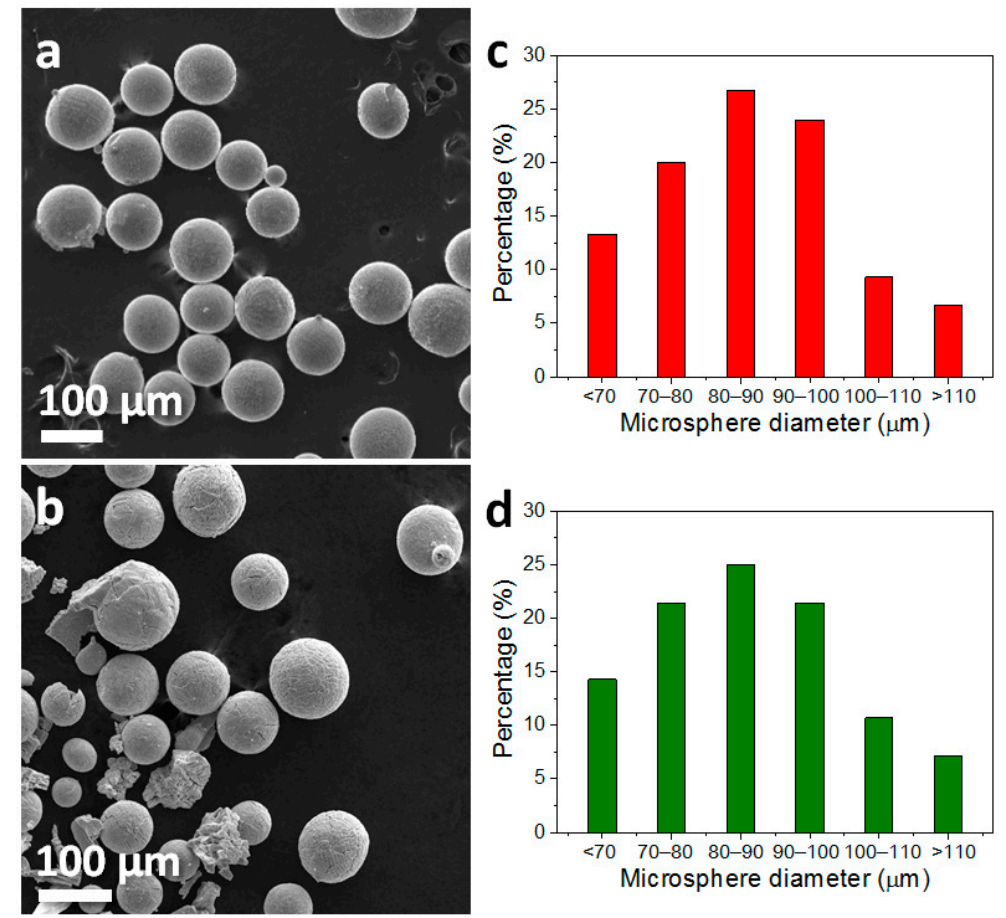

Figure 5. SEM images of the precursor microspheres (a) and the dealloyed microspheres (b). Corresponding size statistics of microspheres before (c) and after (d) dealloying.

Figure 6 shows plane and cross section view SEM images of the dealloyed microspheres. It can be seen (Figure $6 \mathrm{a}, \mathrm{b}$ ) that there are continuous network-like void channels with a width of $\sim 0.6 \mu \mathrm{m}$ 
formed along the grain boundaries of original precursors. That is because $\mathrm{Cu}$ atoms are much easier to remove from grain boundaries with abundant crystal defects [33]. These void channels can also be seen inside the microspheres (Figure 6c), indicating that they distribute throughout the whole microspheres. Moreover, highly magnified SEM images (Figure 6b,d) reveal that both the surface and internal grains show nanoporous structures after dealloying. Figure 6e,f present the ligament and pore size distribution of microspheres after dealloying, showing that the size ranges from 7 to $15 \mathrm{~nm}$ and from 4 to $13 \mathrm{~nm}$ for ligament and pore size, respectively. This result accords with the above pore size distribution curves created by the BJH method.


Figure 6. (a-d) SEM images of microspheres after dealloying in $2 \mathrm{M} \mathrm{HNO}_{3}$ for $24 \mathrm{~h}$ : (a,b) plane view;

$(\mathbf{c}, \mathbf{d})$ cross section view. Ligament (e) and pore (f) size distribution of microspheres after dealloying.

Further analysis by TEM (Figure 7a,b) reveals a nanoscale bicontinuous ligament/pore structure inside the grains, in which the ligament width and pore sizes are $\sim 12 \mathrm{~nm}$ and $\sim 9 \mathrm{~nm}$, respectively. From the above morphological observation, a hierarchical porous structure, containing micro-sized channels along grain boundaries and nanopores inside grains, can be ascribed to the dealloyed microspheres. In addition, the selected area electron diffraction (SAED) pattern in Figure 7c can be ascribed to (111), (200), (220), and (311) diffractions of FCC structure (rather than single-phase Au, $\mathrm{Pt}, \mathrm{Pd}$, or $\mathrm{Cu}$ diffractions), which is consistent with the crystal planes information of the XRD result. The high-resolution TEM image in Figure 7d shows special solid solution characteristics, in which Au-rich, Pt-rich, Pd-rich, and Cu-rich solid solution areas coexist in the ligament [34-37]. The Au, Pt, Pd, and $\mathrm{Cu}$ elements, with FCC structures, easily form a FCC-type solid solution between each other and among three/four elements for their great miscibility, which may be the reason to form a multiphase solid solution structure. In particular, these multiphase solid solutions possess an approximate component ratio and are connected by many dislocations and defects, so that these solid solution areas cannot be completely distinguished from others. As a result, it is multiphase approximatively componential solid solutions (not four-phase separable solid solution) that create. Thus, the diffraction peaks represent a broad single-group FCC pattern rather than sharp multiple-group FCC patterns in the XRD results. 




Figure 7. TEM image (a), corresponding SAED patterns (b), magnified TEM image (c), and high-resolution TEM image (d) of the dealloyed porous microspheres.

In this work, the standard equilibrium electrode potential of $\mathrm{Cu}$ is much lower than that of $\mathrm{Au}, \mathrm{Pt}$, and $\mathrm{Pd}$ [38-40], which offers a great driving force for the selective dissolution of $\mathrm{Cu}$ under free-dealloying conditions. After dealloying for $24 \mathrm{~h}$, the ratio of remaining $\mathrm{Cu}$ and the other three elements is nearly equal, and the calculated physical parameters in Table 1 satisfy the empirical rules for forming HEAs. In particular, the as-formed nanoporous structure presents a multiphase approximatively componential solid solution characteristic, which is different from the traditional single-phase or two-phase solid solution HEAs. To differentiate, we call it quasi-HEAs. The as-fabricated nanoporous quasi-HEAs possess plentiful dislocations and defects between two neighboring solid solution areas and a high specific surface area, which may be applied in wide chemical fields [41-43]. The higher resolution characterization of quasi-HEAs needs to be examined in future work. For example, spherical aberration-corrected high-angle annular dark field (HAADF) STEM images of nanoporous metals could reveal surface atoms with different coordination numbers [44]. Atomically resolved elemental mapping of the surface of nanoporous electrocatalyst could uncover the surface atomic change before and after a catalytic reaction [45]. With the help of these higher resolution tests, some chemical reaction mechanisms can be clearly revealed. Thus, the exploitation and development of chemical properties of HEAs can be promoted.

\section{Conclusions}

We developed a facile route to fabricate nanoporous noble metal quasi-HEA microspheres by a melt-spinning and dealloying process. The material presents a hierarchical porous structure with a high specific surface area and a multiphase approximatively componential solid solution characteristic with a broad single-group FCC XRD pattern. Metallic elements such as $\mathrm{Au}, \mathrm{Pt}, \mathrm{Pd}, \mathrm{Ag}, \mathrm{Ir}, \mathrm{Rh}$, $\mathrm{Cu}$, and Ni with FCC structure can be selected for developing other porous quasi-HEAs by using this route. Moreover, the work may stimulate the overall development of quasi-HEAs in various chemical applications. 
Author Contributions: Data curation, L.Y. and Y.L.; Funding acquisition, Z.W.; Investigation, L.Y. and Y.L.; Methodology, Z.W. and W.Z.; Project administration, Z.W.; Resources, C.Q.; Supervision, W.Z. and C.Q.; Writing—original draft, L.Y.; Writing—review \& editing, Z.W.

Funding: This work was financially supported by the Key Project of Science \& Technology Research of Higher Education Institutions of Hebei Province, China (ZD2018059) and the Natural Science Foundation of Hebei Province, China (E2015202081).

Conflicts of Interest: The authors declare no conflict of interest.

\section{References}

1. Zou, Y.; Ma, H.; Spolenak, R. Ultrastrong ductile and stable high-entropy alloys at small scales. Nat. Commun. 2015, 6, 7748. [CrossRef]

2. Zhang, W.R.; Liaw, P.K.; Zhang, Y. Science and technology in high-entropy alloys. Sci. China Mater. 2018, 61, 2-22. [CrossRef]

3. Gludovatz, B.; Hohenwarter, A.; Catoor, D.; Chang, E.H.; George, E.P.; Ritchie, R.O. A fracture-resistant high-entropy alloy for cryogenic applications. Science 2014, 345, 1153-1158. [CrossRef]

4. Li, Z.M.; Pradeep, K.G.; Deng, Y.; Raabe, D.; Tasan, C.C. Metastable high-entropy dual-phase alloys overcome the strength-ductility trade-off. Nature 2016, 534, 227-230. [CrossRef] [PubMed]

5. Tracy, C.L.; Park, S.; Rittman, D.R.; Zinkle, S.J.; Bei, H.B.; Lang, M.; Ewing, R.C.; Mao, W.L. High pressure synthesis of a hexagonal close-packed phase of the high-entropy alloy CrMnFeCoNi. Nat. Commun. 2017, 8, 15634. [CrossRef] [PubMed]

6. Niu, C.N.; LaRosa, C.R.; Miao, J.S.; Mills, M.J.; Ghazisaeidi, M. Magnetically-driven phase transformation strengthening in high entropy alloys. Nat. Commun. 2018, 9, 1363. [CrossRef] [PubMed]

7. Jo, Y.H.; Jung, S.; Choi, W.M.; Sohn, S.S.; Kim, H.S.; Lee, B.J.; Kim, N.J.; Lee, S. Cryogenic strength improvement by utilizing room-temperature deformation twinning in a partially recrystallized VCrMnFeCoNi high-entropy alloy. Nat. Commun. 2017, 8, 15719. [CrossRef] [PubMed]

8. Yao, Y.G.; Huang, Z.N.; Xie, P.F.; Lacey, S.D.; Jacob, R.J.; Xie, H.; Chen, F.J.; Nie, A.M.; Pu, T.C.; Rehwoldt, M.; et al. Carbothermal shock synthesis of high-entropy-alloy nanoparticles. Science 2018, 359, 1489-1494. [CrossRef] [PubMed]

9. Dan, Z.H.; Qu, J.H.; Yang, Y.L.; Qin, F.X.; Chang, H. Evolution of nanoporous surface layers on gas-atomized $\mathrm{Ti}_{60} \mathrm{Cu}_{39} \mathrm{Au}_{1}$ powders during dealloying. Nanomaterials 2018, 8, 581. [CrossRef] [PubMed]

10. Wang, Z.F.; Liu, J.Y.; Qin, C.L.; Yu, H.; Xia, X.C.; Wang, C.Y.; Zhang, Y.S.; Hu, Q.F.; Zhao, W.M. Dealloying of Cu-based metallic glasses in acidic solutions: Products and energy storage applications. Nanomaterials 2015, 5, 697-721. [CrossRef]

11. Qiu, H.J.; Gao, J.J.; Chiang, F.K.; Wen, Y.R.; Yao, A.Y.; Du, P.; Fang, G.; Wang, J.Q.; Liu, X.J. A general and scalable approach to produce nanoporous alloy nanowires with rugged ligaments for enhanced electrocatalysis. J Mater. Chem. A 2018, 6, 12541-12550. [CrossRef]

12. Zheng, D.H.; Zhao, F.; Li, Y.Y.; Qin, C.L.; Zhu, J.S.; Hu, Q.F.; Wang, Z.F.; Inoue, A. Flexible NiO micro-rods/nanoporous $\mathrm{Ni} /$ metallic glass electrode with sandwich structure for high performance supercapacitors. Electrochim. Acta 2019, 297, 767-777. [CrossRef]

13. Liu, S.Y.; Pang, F.J.; Zhang, Q.W.; Guo, R.J.; Wang, Z.F.; Wang, Y.C.; Zhang, W.Q.; Ou, J.Z. Stable nanoporous $\mathrm{Sn} / \mathrm{SnO}_{2}$ composites for efficient electroreduction of $\mathrm{CO}_{2}$ to formate over wide potential range. Appl. Mater. Today 2018, 13, 135-143. [CrossRef]

14. Zhao, W.M.; Fei, P.Y.; Zhang, X.M.; Zhang, Y.G.; Qin, C.L.; Wang, Z.F. Porous $\mathrm{TiO}_{2} / \mathrm{Fe}_{2} \mathrm{O}_{3}$ nanoplate composites prepared by de-alloying method for Li-ion batteries. Mater. Lett. 2018, 211, 254-257. [CrossRef]

15. Wang, Z.F.; Zhang, X.M.; Yan, Y.H.; Zhang, Y.G.; Wang, Y.C.; Qin, C.L.; Bakenov, Z. Nanoporous $\mathrm{GeO}_{2} / \mathrm{Cu} / \mathrm{Cu}_{2} \mathrm{O}$ network synthesized by dealloying method for stable Li-ion storage. Electrochim. Acta 2019, 300, 363-372. [CrossRef]

16. Qin, C.L.; Zhang, Y.S.; Wang, Z.F.; Xiong, H.Q.; Yu, H.; Zhao, W.M. One-step synthesis of CuO@brass foil by dealloying method for low-cost flexible supercapacitor electrodes. J. Mater. Sci. Mater. Electron. 2016, 27, 9206-9215. [CrossRef] 
17. Zhang, Q.; Kusada, K.; Wu, D.S.; Yamamoto, T.; Toriyama, T.; Matsumura, S.; Kawaguchi, S.; Kubota, Y.; Kitagawa, H. Selective control of fcc and hcp crystal structures in Au-Ru solid-solution alloy nanoparticles. Nat. Commun. 2018, 9, 510. [CrossRef]

18. Sarker, M.S.I.; Nakamura, T.; Sato, S. All-proportional solid-solution Rh-Pd-Pt alloy nanoparticles by femtosecond laser irradiation of aqueous solution with surfactant. J. Nanopart. Res. 2015, 17, 259. [CrossRef]

19. Yew, J.W.; Chen, S.K.; Lin, S.J.; Gan, J.Y.; Chin, T.S.; Shun, T.T.; Tsau, C.H.; Chang, S.Y. Nanostructured high-entropy alloys with multiple principal elements: Novel alloy design concepts and outcomes. Adv. Eng. Mater. 2004, 6, 299-303.

20. Ma, D.C.; Yao, M.J.; Pradeep, K.G.; Tasan, C.C.; Springer, H.; Raabe, D. Phase stability of non-equiatomic CoCrFeMnNi high entropy alloys. Acta. Mater. 2015, 98, 288-296. [CrossRef]

21. Zhang, Y.; Zuo, T.T.; Tang, Z.; Gao, M.C.; Dahmen, K.A.; Liaw, P.K.; Lu, Z.P. Microstructures and properties of high-entropy alloys. Prog. Mater. Sci. 2014, 61, 1-93. [CrossRef]

22. Miracle, D.B.; Senkov, O.N. A critical review of high entropy alloys and related concepts. Acta. Mater. 2017, 122, 448-511. [CrossRef]

23. Kao, Y.F.; Chen, T.J.; Chen, S.K.; Yeh, J.W. Microstructure and mechanical property of as-cast, -homogenized, and -deformed $\mathrm{Al}_{x} \mathrm{CoCrFeNi}(0 \leq x \leq 2)$ high-entropy alloys. J. Alloys Compd. 2009, 488, 57-64. [CrossRef]

24. Wu, Z.; Bei, H.; Otto, F.; Pharr, G.M.; George, E.P. Recovery, recrystallization, grain growth and phase stability of a family of FCC-structured multi-component equiatomic solid solution alloys. Intermetallics 2014, 46, 131-140. [CrossRef]

25. Sohn, S.W.; Liu, Y.H.; Liu, J.B.; Gong, P.; Prades-Rodel, S.; Blatter, A.; Scanley, B.E.; Broadbridge, C.C.; Schroers, J. Noble metal high entropy alloys. Scr. Mater. 2017, 126, 29-32. [CrossRef]

26. Ge, X.B.; Chen, L.Y.; Zhang, L.; Wen, Y.R.; Hirata, A.; Chen, M.W. Nanoporous metal enhanced catalytic activities of amorphous molybdenum sulfide for high-efficiency hydrogen production. Adv. Mater. 2014, 26, 3100-3104. [CrossRef]

27. Wang, R.Y.; Liu, J.G.; Liu, P.; Bi, X.X.; Yan, X.L.; Wang, W.X.; Ge, X.B.; Chen, M.W.; Ding, Y. Dispersing Pt atoms onto nanoporous gold for high performance direct formic acid fuel cells. Chem. Sci. 2014, 5, 403-409. [CrossRef]

28. Tressaud, A.; Khairoun, H.; Touhara, H.; Watanabe, N. X-ray photoelectron spectroscopy of palladium fluorides. Z. Anorg. Allg. Chem. 1986, 540, 291-299. [CrossRef]

29. Du, Y.X.; Ni, K.; Zhai, Q.X.; Yun, Y.P.; Xu, Y.J.; Sheng, H.T.; Zhu, Y.W.; Zhu, M.Z. Facile air oxidative induced dealloying of hierarchical branched $\mathrm{PtCu}$ nanodendrites with enhanced activity for hydrogen evolution. Appl. Catal. A General 2018, 557, 72-78. [CrossRef]

30. Chen, L.Y.; Guo, H.; Fujita, T.; Hirata, A.; Zhang, W.; Inoue, A.; Chen, M.W. Nanoporous PdNi bimetallic catalyst with enhanced electrocatalytic performances for electro-oxidation and oxygen reduction reactions. Adv. Funct. Mater. 2011, 21, 4364-4370. [CrossRef]

31. Xu, C.X.; Wang, R.Y.; Chen, M.W.; Zhang, Y.; Ding, Y. Dealloying to nanoporous Au/Pt alloys and their structure sensitive electrocatalytic properties. Phys. Chem. Chem. Phys. 2010, 12, 239-246. [CrossRef]

32. Dong, C.Q.; Kou, T.Y.; Gao, H.; Peng, Z.Q.; Zhang, Z.H. Eutectic-derived mesoporous Ni-Fe-O nanowire network catalyzing oxygen evolution and overall water splitting. Adv. Eng. Mater. 2018, 8, 1701347. [CrossRef]

33. Liu, X.; Du, J.; Shao, Y.; Zhao, S.F.; Yao, K.F. One-pot preparation of nanoporous Ag-Cu@Ag core-shell alloy with enhanced oxidative stability and robust antibacterial activity. Sci. Rep. 2017, 7, 10249. [CrossRef]

34. Gong, M.X.; Fu, G.T.; Chen, Y.; Tang, Y.W.; Lu, T.H. Autocatalysis and selective oxidative etching induced synthesis of platinum-copper bimetallic alloy nanodendrites electrocatalysts. ACS Appl. Mater. Inter. 2014, 6, 7301-7308. [CrossRef]

35. Xing, Y.L.; Wang, S.B.; Fang, B.Z.; Feng, Y.F.; Zhang, S.C. Three-dimensional nanoporous $\mathrm{Cu}_{65} \mathrm{Sn}_{5} / \mathrm{Cu}$ composite from dealloying as anode for lithium ion batteries. Micropor. Mesopor. Mat. 2018, 261, $237-243$. [CrossRef]

36. Hong, J.W.; Kang, S.W.; Choi, B.S.; Kim, D.; Lee, S.B.; Han, S.W. Controlled synthesis of Pd-Pt alloy hollow nanostructures with enhanced catalytic activities for oxygen reduction. ACS Nano 2012, 6, 2410-2419. [CrossRef] 
37. Liu, K.; Bai, Y.C.; Zhang, L.; Yang, Z.B.; Fan, Q.K.; Zheng, H.Q.; Yin, Y.D.; Gao, C.B. Porous Au-Ag nanospheres with high-density and highly accessible hotspots for SERS analysis. Nano Lett. 2016, 16, 3675-3681. [CrossRef]

38. Zhou, Q.X.; Qi, L.; Yang, H.X.; Xu, C.X. Hierarchical nanoporous platinum-copper alloy nanoflowers as highly active catalysts for the hydrolytic dehydrogenation of ammonia borane. J. Colloid Inerf. Sci. 2018, 513, 258-265. [CrossRef]

39. Xu, Y.; Yiu, P.M.; Shan, G.C.; Shibayama, T.; Watanabe, S.; Ohnuma, M.; Huang, W.; Shek, C.H. 3D nanoporous gold with very low parting limit derived from Au-based metallic glass and enhanced methanol electro-oxidation catalytic peiformance induced by metal migration. ChemNanoMat 2018, 4, 88-97. [CrossRef]

40. Shi, S.; Markmann, J.; Weissmuller, J. Actuation by hydrogen electrosorption in hierarchical nanoporous palladium. Philos. Mag. 2017, 97, 1571-1587. [CrossRef]

41. Hou, Y.; Chen, L.Y.; Liu, P.; Kang, J.L.; Fujita, T.; Chen, M.W. Nanoporous metal based flexible asymmetric pseudocapacitors. J. Mater. Chem. A 2014, 2, 10910-10916. [CrossRef]

42. Zhang, W.Q.; He, J.; Liu, S.Y.; Niu, W.X.; Liu, P.; Zhao, Y.; Pang, F.J.; Xi, W.; Chen, M.W.; Zhang, W.; et al. Atomic origins of high electrochemical $\mathrm{CO}_{2}$ reduction efficiency on nanoporous gold. Nanoscale 2018, 10, 8372-8376. [CrossRef]

43. Pang, F.J.; Wang, Z.F.; Zhang, K.; He, J.; Zhang, W.Q.; Guo, C.X.; Ding, Y. Bimodal nanoporous $\mathrm{Pd}_{3} \mathrm{Cu}_{1}$ alloy with restrained hydrogen evolution for stable and high yield electrochemical nitrogen reduction. Nano Energy 2019, 58, 834-841. [CrossRef]

44. Liu, P.; Guan, P.F.; Hirata, A.; Zhang, L.; Chen, L.Y.; Wen, Y.R.; Ding, Y.; Fujita, T.; Erlebacher, J.; Chen, M.W. Visualizing under-coordinated surface atoms on 3D nanoporous gold catalysts. Adv. Mater. 2016, 28, 1753-1759. [CrossRef]

45. Li, J.; Yin, H.M.; Li, X.B.; Okunishi, E.; Shen, Y.L.; He, J.; Tang, Z.K.; Wang, W.X.; Yücelen, E.; Li, C.; et al. Surface evolution of a Pt-Pd-Au electrocatalyst for stable oxygen reduction. Nat. Energy 2017, 2, 17111. [CrossRef] 